\title{
ANÁLISIS COMPARATIVO DEL PRESUPUESTO GENERAL DEL ESTADO Y SU INFLUENCIA EN LA POLÍTICA FISCAL EN EL ECUADOR, PERÍODO 2019-2020
}

\author{
COMPARATIVE ANALYSIS OF THE GENERAL STATE BUDGET AND ITS INFLUENCE \\ ON FISCAL POLICY IN ECUADOR, PERIOD 2019-2020
}

LuIS ANDRÉs Moyón SÁnCHEZ Investigador independiente Riobamba - Ecuador

ORCID: https://orcid.org/0000-0003-3280-4911

Correo electrónico: andyecofin2022@gmail.com

Guadalupe Alejandra Robalino Rivadeneira

Escuela Superior Politécnica de Chimborazo Riobamba - Ecuador

ORCID: https://orcid.org/0000-0003-1397-814X Correo electrónico: guadalupe.robalino@espoch.edu.ec

Doris Nataly Gallegos Santillán Universidad Nacional de Chimborazo Riobamba - Ecuador ORCID: https://orcid.org/0000-0001-7938-2280

Correo electrónico:dgallegos@unach.edu.ec

\section{RESUMEN}

Objetivo: Realizar un análisis comparativo del Presupuesto $\mathrm{Ge}$ neral del Estado y su influencia en el mejoramiento de la calidad de vida de los ecuatorianos en función del gasto público. Método: El tipo de investigación fue descriptivo porque permitió mediante la observación determinar las características de las variables estudiadas y aplicadas, ya que se utilizó el conocimiento para realizar un análisis comparativo cuantitativo y porcentual entre los grupos de ingresos y gastos de los Presupuestos Generales del Estado. Resultados: Los resultados muestran que aplicando una política monetaria restrictiva se ha provocado incremento del desempleo, menor cobertura de servicios sociales y pobreza. Conclusiones: Optimizar el gasto público es posible, pero el camino de la austeridad no puede tener como única vía la reducción de la masa salarial.

Palabras clave: Presupuesto; gasto público; política fiscal; inversión; deuda.

\begin{abstract}
Objective: Carry out a comparative analysis of the General State Budget and its influence on improving the quality of life of Ecuadorians based on public spending. Method: The type of research was descriptive because it allowed observation to determine the characteristics of the variables studied and applied, since the knowledge was used to carry out a quantitative and percentage comparative analysis between the income and expenditure groups of the General State Budgets. Results: The results show that applying a restrictive monetary policy has caused an increase in unemployment, less coverage of social services and poverty. Conclusions: Optimizing public spending is possible, but the path of austerity cannot be the only way to reduce the wage bill.
\end{abstract}

Keywords: Budget; public spending; fiscal policy; investment; debt.

(c) Los autores. Este artículo es publicado por la Revista Quipukamayoc, Universidad Nacional Mayor de San Marcos. Este es un artículo de acceso abierto, distribuido bajo los términos de la Licencia Creative Commons Atribución-NoComercial-Compartirlgual 4.0 Internacional.(http://creativecommons.org/licenses/by-nc-sa/4.0/), que permite el uso no comercial, distribución y reproducción en cualquier medio, siempre que la obra original sea debidamente citadas. 


\section{INTRODUCCIÓN}

Luego de que el Ecuador dolarizó su economía en el año 2000 , la política fiscal se convirtió en el principal instrumento del manejo de la política económica. Las finanzas públicas a través del Presupuesto General de Estado buscan equilibrar la economía del país. Sin embargo, luego de aplicar una política fiscal expansiva durante el Gobierno del expresidente Correa, se dio paso a una política fiscal restrictiva donde la reducción del gasto público y el incremento de la deuda pública han sido los factores determinantes del manejo actual de la economía del gobierno del presidente Lenin Moreno. El equilibrio fiscal se ha visto comprometido en los últimos años y se han propuesto medidas de austeridad, que van desde la reducción de entidades y servidores del sector público, reducción en la compra de bienes y servicios, hasta la remisión tributaria y medidas de apoyo al sector productivo y al emprendimiento, con la finalidad de generar empleo para la sociedad.

Este trabajo de investigación tiene como propósito revisar el Presupuesto General del Estado que entró en vigencia por el ministerio de la ley, sin el filtro del debate, en los años 2019 y 2020 de una manera técnica que permita establecer las fuentes de ingresos y su incidencia en el gasto público, de tal forma que se puedan establecer políticas y alternativas para lograr un equilibrio en las finanzas públicas sin dejar de brindar servicios públicos de calidad a través de planes de inversión y reducir el impacto del servicio de la deuda externa del país.

La política fiscal no es más que la elección de los impuestos y manejo del gasto por parte de un gobierno, y constituye una herramienta para determinar el nivel de impuestos (ingresos) y consumo (gastos) que desea tener para influir en el nivel de producción (Blanchard et al., 2012).

Así, la política fiscal determina los ingresos y gastos públicos que sirven para lograr objetivos de eficiencia, redistribución y estabilización; por consiguiente, el manejo fiscal se considera una herramienta de estabilización económica, que permita entender cómo el gasto público y los impuestos afectan a la producción y al empleo de un país; la política fiscal se convierte en uno de los elementos que el Estado puede controlar para moderar las fluctuaciones y estabilizar la economía en un momento determinado.

Ruiz del Castillo (2010) afirma lo siguiente:

La tarea de estabilización económica por parte de la política fiscal puede ser desarrollada por el sector público al llevar adelante dos de sus habituales tareas: productor de bienes $y$ servicios $y$ de redistribuidor de ingresos, y mediante acciones de política de tipo discrecional o de la operación de los llamados estabilizadores fiscales automáticos.

En su rol de productor de bienes y servicios, la política fiscal del sector público tendrá efectos estabilizadores si logra, mediante sus operaciones de inversión $y$ consumo, que las fluctuaciones de la demanda nacional sean menores que las fluctuaciones de la demanda del sector privado a lo largo del ciclo económico, contribuyendo a sostener la demanda nacional en fases de recesión y a limitar su crecimiento en fases de expansión.

En su función de redistribución de ingresos, la política fiscal tendrá efectos estabilizadores, por intermedio de los sistemas de transferencias y tributarios, si logra que el ingreso disponible del sector privado fluctúe en menor proporción que el ingreso nacional a lo largo del ciclo económico; es decir, si consigue atenuar las fluctuaciones del ingreso disponible de los agentes privados, ayudando a sostenerlo en etapas de recesión y a morigerar su crecimiento en etapas de expansión. Además, es posible sostener que esto sería en sí mismo un objetivo deseable si los agentes privados valoran positivamente un flujo estable de ingreso. (p.10)

Por lo tanto, la política fiscal se encarga de la gestión de los recursos del Estado y su administración, quién controla los niveles de gasto e ingresos mediante variables como los impuestos y el gasto público para mantener un nivel de estabilidad.

Para los autores Dornbusch y Fischer (1995) existen dos tipos de política fiscal:

Politica Fiscal Expansiva: que genera un déficit en los Presupuestos de Estado (es decir, una situación en que el gasto público es superior a los ingresos fiscales) que se financia mediante la emisión de deuda pública. Los mecanismos a usar son: 1) aumentar el gasto público, para aumentar la producción y reducir el paro, o 2) aumentar el gasto privado, bajando los impuestos para aumentar la renta disponible de los agentes económicos privados, lo que provocará un mayor consumo de las personas y una mayor inversión de las empresas (en definitiva, un aumento de la demanda económica). Se denomina 'expansiva' porque se ejecuta para estimular el crecimiento económico y crear empleo.

Política Fiscal Restrictiva: que genera un superávit en los Presupuestos del Estado (es decir, una situación en que el gasto público es inferior a los ingresos fiscales). Los mecanismos son los contrarios que en la expansiva: 1) reducir el gasto público, para bajar 


\begin{abstract}
la demanda y por tanto la producción, o 2) reducir el gasto privado, subiendo los impuestos para que los ciudadanos tengan una renta menor, disminuyan su consumo y, con ello, la demanda económica. Se ejecuta cuando la economía conoce un período de excesiva expansión y tiene necesidad de frenarse para evitar el aumento de los precios (inflación). (p. 152)
\end{abstract}

La calidad del gasto público abarca aquellos elementos que garantizan un uso eficaz y eficiente de los recursos públicos, con los objetivos de elevar el potencial de crecimiento de la economía y, en el caso particular de América Latina y el Caribe, de asegurar grados crecientes de equidad distributiva. La medición de la calidad del gasto público debe incorporar la multidimensionalidad de los factores que inciden el logro de los objetivos macroeconómicos y de política fiscal (Armijo y Espada, 2014).

Entre las funciones asignadas generalmente a la política fiscal, una de las más importantes consiste en asegurar la estabilidad macroeconómica. Es así que la recomendación básica consiste en moderar el gasto público durante las expansiones económicas y asegurar un nivel mínimo del mismo durante las recesiones. En particular, debe evitarse la vulnerabilidad del gasto social, que tiende a ser más procíclico que el resto de los componentes del gasto (CEPAL, 2006).

El presupuesto es considerado como una herramienta de carácter financiero, económico y social que permite a la autoridad estatal planear, programar y proyectar los ingresos y gastos públicos en un periodo fiscal, a fin de que lo programado o proyectado en materia presupuestal sea lo más cercano a la realidad (Romero, 2012).

\section{MATERIALES Y MÉTODOS}

El tipo de investigación que se aplicó es el descriptivo, ya que permitió mediante la observación determinar las características de las variables estudiadas y aplicadas. Asimismo, utilizó el conocimiento para realizar un análisis comparativo cuantitativo y porcentual entre los grupos de ingresos y gastos de los Presupuestos Generales del Estado. Se recurrió al método científico porque las ideas, conceptos, y teorías expuestas en este trabajo de investigación son verificables como válidos, además que sirvió para recopilar la información necesaria sobre los Presupuestos Generales del Estado. El método comparativo sirvió para comparar cada uno de los resultados estudiados en períodos de tiempo establecidos en este proyecto de investigación. El método analítico permitió el análisis y observación de un hecho particular el cual se pudo explicar y argumentar efectivamente. Además, con el método sintético se estableció un proceso de razonamiento que tendió a reconstruir un todo, a partir de los elementos distinguidos por el análisis en el presente previo al análisis de la situación actual, la asignación presupuestaria en cada grupo gasto en función de los ingresos obtenidos, el endeudamiento y la inversión pública y su correcta evaluación.

\section{RESULTADOS}

Según lo establecido en la Constitución Política del Ecuador y el Código Orgánico de Planificación y Finanzas Publicas, el Plan Nacional de Desarrollo es el instrumento al que se sujetarán las políticas, programas y proyectos públicos; la programación y ejecución del Presupuesto General del Estado; y, la inversión, además de la asignación de los recursos públicos. En tal virtud, el Presupuesto General del Estado es el instrumento para la determinación y gestión de los ingresos y egresos de todas las entidades que constituyen las diferentes Funciones del Estado(Constitución, 2018).

Bajo este antecedente, el 31 de octubre de 2019, el Ministerio de Economía envió la Proforma 2020 a la Asamblea para su discusión y aprobación. El 27 de noviembre, la Asamblea Nacional aprobó una resolución en la cual hizo 17 observaciones a la Proforma del Presupuesto General del Estado remitida por el Ejecutivo. El 5 de diciembre de 2019, el Presidente de la República remitió el cumplimiento a las observaciones presentadas a la Asamblea Nacional. El 17 de diciembre de 2019 se discutió en la Asamblea Nacional y no se aprobó. En virtud de lo establecido en la Constitución, el Presidente solicitó la publicación de la Proforma Presupuestaria que entró en vigencia el 27 de diciembre de 2019. Esta Proforma Presupuestaria para el año 2020 asciende al valor de USD 35498042 millones; se estima que el Producto Interno Bruto (PIB) para este Ejercicio Fiscal alcance un monto de USD 110434442 millones (Registro Oficial de la República del Ecuador, 2019).

Presupuesto 2020 vs. Presupuesto 2019, según variable macroeconómicas

En la tabla 1, se muestra la comparación del Presupuesto 2020 con el del año inmediatamente anterior (2019) considerando las principales variables macroeconómicas.

El Ministerio de Finanzas estableció algunos supuestos macroeconómicos para el Ejercicio Fiscal 2020; el PIB nominal se fijó en USD 110,434 millones con una reducción del 2,35\% con relación al PIB nominal del año 2019 que se estableció en USD 113,097 millones. En términos constantes, representa un crecimiento real del PIB de 0,57\%; se estima que la tasa de variación del deflactor que se alcanzará en el 2020 será del 1,00 \% mientras que en el año 2019 fue del 1,87 \%; y la inflación promedio para el año 2020 se prevé alcanzará el 0,84\% mientras que en el año 2019 la proyección fue del 1,07 \%. 
En el presupuesto del año 2020, el sector petrolero prevé una producción anual de crudo de 194,78 millones de barriles, con un precio promedio de exportación del crudo de USD 51,30 por barril; si comparamos con lo previsto en el presupuesto del año 2019 de 206,21 millones de barriles, se estima una reducción de producción anual de 11,43 millones de barriles, es decir un 5,54 \% (MEF, 2020).

Presupuesto 2020 vs. Presupuesto 2019, según ingresos y egresos totales

La tabla 2 muestra la comparación de Presupuesto 2020 con el Presupuesto 2019 en función de los ingresos y egresos.

En el Presupuesto 2020, los ingresos suman USD 26.545,98 millones, mientras que los egresos USD 29.929,89 millones, observándose un déficit global de USD 3.383,91 millones, cifra que representa $3,06 \%$ del PIB, el mismo que será cubierto mediante operaciones de financiamiento público.

En el Presupuesto 2019, los ingresos sumaron USD 22.361,51 millones, mientras que los egresos fueron USD 25.098,45 millones, observándose un déficit global de USD 2.736,94 millones, cifra que representa $2,42 \%$ del PIB, el mismo que se está cubriendo mediante operaciones de financiamiento público.

En el Presupuesto 2020 se contempla para inversión pública USD 3.624,73 millones, mientras que en el Presupuesto 2019 se contempló una inversión pública de USD 3.429,76 millones. Se nota con un ligero incremento de USD 194,97 millones; recursos dirigidos a la ejecución de programas, proyectos de arrastre y los programas nuevos que se incluyen en el Plan Anual de Inversión.

Presupuesto 2020 vs. Presupuesto 2019, según tipo de ingresos

En la tabla 3, se muestra el análisis comparativo del Presupuesto 2020 con el Presupuesto del año 2019 considerando tipos de ingresos.

El Presupuesto General del Estado en 2020, asciende al valor de USD 35.498,42 millones, de los cuales USD 23.853,05 millones corresponden a ingresos corrientes que representan el 67,19 \% de la estructura total; mientras que los ingresos de capital estimados en USD 2.712,76 millones, aportan con el 7,64\%; en tanto que el restante $25,16 \%$ constituye los ingresos de financiamiento con un valor de USD 8.932,61 millones.

Para el año 2019, los ingresos y el financiamiento del Presupuesto General del Estado ascendieron a un monto de USD 35.529,39 millones, de los cuales USD 23.784,21 millones corresponden a ingresos corrientes, que representan el $66,94 \%$ de la estructura total; mientras que los ingresos de capital, estimados en USD 2.825,93 millones, aportan con el 7,95 \%; y, el 25,10 \% restante se pretendió obtener mediante financiamiento con un valor de USD $8.919,25$ millones.

Tabla 1

Principales variables macroeconómicas Presupuesto 2020 vs. Presupuesto 2019

\begin{tabular}{lcc}
\hline VARIABLES MACROECONÓMICAS & PROFORMA 2019 & PROFORMA 2020 \\
\hline PIB nominal ( USD en millones) & 113.097 & 110.434 \\
Crecimiento real del PIB & $1,43 \%$ & $0,57 \%$ \\
Tasa de variación de deflactor de PIB & $1,87 \%$ & $1,00 \%$ \\
Inflación & $1,07 \%$ & $0,84 \%$ \\
Importaciones no petroleras (USD millones FOB) & 18.253 & 17.464 \\
Volumen de producción fiscalizada de petróleo (millones de barriles) & 206,21 & 194,78 \\
Precio promedio de exportaciones de crudo (USD-barril) & 50,05 & 51,3 \\
Precio promedio de exportaciones de derivados (USD-barril) & 63,34 & 49,87 \\
\hline
\end{tabular}

Fuente: MEF, BCE, Ministerio de Energía y Recursos No Renovable.

Tabla 2

Déficit total: Presupuesto 2020 vs. Presupuesto 2019 (en millones de dólares)

\begin{tabular}{|c|c|c|c|c|}
\hline \multirow[b]{2}{*}{ TOTALES } & \multirow[b]{2}{*}{2020} & \multirow[b]{2}{*}{2019} & \multicolumn{2}{|c|}{ VARIACION } \\
\hline & & & ABSOLUTA & RELATIVA \\
\hline INGRESOS TOTALES & $26.545,98$ & $22.361,51$ & $4.184,47$ & $15,76 \%$ \\
\hline EGRESOS TOTALES & $29.929,89$ & $25.098,45$ & $4.831,44$ & $16,14 \%$ \\
\hline DEFICIT / SUPERAVIT GLOBAL & $-3.383,91$ & $-2.736,94$ & $-646,97$ & $19,12 \%$ \\
\hline
\end{tabular}

Fuente: Ministerio de Economía y Finanzas 
Los recursos de financiamiento en el año 2020 suman USD 8.932,61 millones, de los cuales USD 4.709,82 millones corresponden a deuda externa que representan el $13,27 \%$ del total del Presupuesto General del Estado y el $4,26 \%$ del PIB; dentro de la estructura de la deuda externa, las fuentes de financiamiento se encuentran distribuidas entre préstamos con Organismos Multilaterales por USD 2.687,97 millones, operaciones con otras entidades internacionales por USD 1.819,28 millones, y con Gobiernos por USD 202,57 millones.

La deuda interna de USD 1.955,11 millones provienen del financiamiento interno, proviene de la negociación y entrega directa de papeles fiduciarios colocados en el mercado financiero nacional. El resto de ítems de esta categoría, corresponden a saldos disponibles, principalmente de préstamos que ascienden a USD 2.267,68 millones.

Respecto al financiamiento público en 2019, corresponde a deuda interna y externa (grupo 36) USD 8.148,26 millones, con una contribución al PGE de 22,93 \%; el financiamiento externo se estima en un monto de USD 7.385,26 millones, que representan el 20,79\% del total del Presupuesto General del Estado y el 6,53 \% del PIB; dentro de la estructura de la deuda externa, las fuentes de financiamiento se encuentran distribuidas entre: colocación de Títulos Valores en el mercado internacional USD 1.750 millones; préstamos con Organismos Multilaterales por
USD 916,04 millones; operaciones con otras entidades internacionales por USD 2.925,53 millones; y, Gobiernos por USD 1.793,69 millones.

El financiamiento interno proviene de la negociación y entrega directa de papeles fiduciarios colocados en el mercado financiero nacional y de los préstamos del Banco del Estado. Para el año 2019 llega a USD 762,99 millones, que constituye el 0,67 \% del PIB y el 2,15 \% del total del PGE.

Presupuesto 2020 vs. Presupuesto 2019, según egresos totales, gastos en personal y en bienes y servicios

La tabla 4 muestra el análisis del gasto público 2020 en comparación con el 2019 considerando los gastos en personal, las instituciones que incurren en un mayor gasto y los gastos en bienes y servicios.

El gasto público en 2020, lo analizamos desde los egresos de personal que ascienden a USD 8.897,02 millones, representa un 25,06 \% del total de egresos PGE; se reduce la carga fiscal asociada a sueldos y salarios de los servidores públicos, con el fin de disminuir la masa salarial, a través de la optimización de las estructuras organizacionales burocráticas (figura 1).

En la tabla 4, corresponden a remuneraciones unificadas de los Ministerios de Educación (USD 2.361,25 millones), Salud Pública (USD 1.505,80 millones), Defensa Nacional

Tabla 3

Tipo de ingresos: Presupuesto 2020 vs. Presupuesto 2019 (en millones de dólares)

\begin{tabular}{lcccc}
\hline & & \multicolumn{2}{c}{ VARIACIÓN } \\
\hline INGRESOS & $\mathbf{2 0 2 0}$ & $\mathbf{2 0 1 9}$ & ABSOLUTA & RELATIVA \\
\hline CORRIENTES & $23.853,05$ & $23.784,21$ & 68,84 & $0,29 \%$ \\
FINANITAL & $2.712,76$ & $2.825,93$ & $-113,17$ & $-4,17 \%$ \\
\hline TOTAL & $8.932,61$ & $8.919,25$ & 13,36 & $0,15 \%$ \\
\hline
\end{tabular}

Fuente: Ministerio de Economía y Finanzas

Tabla 4

Análisis comparativo egresos por instituciones de mayor gasto en personal: Presupuesto 2020 vs Presupuesto 2019 (en millones de dólares)

\begin{tabular}{|c|c|c|c|c|}
\hline \multirow[b]{2}{*}{ GASTOS EN PERSONAL } & \multirow[b]{2}{*}{2020} & \multirow[b]{2}{*}{2019} & \multicolumn{2}{|c|}{ VARIACIÓN } \\
\hline & & & ABSOLUTA & RELATIVA \\
\hline MINISTERIO DE EDUCACIÓN & $2.361,25$ & $2.492,67$ & $-131,42$ & $-5,57 \%$ \\
\hline MINISTERIO DE SALUD & $1.505,80$ & $1.605,25$ & $-99,45$ & $-6,60 \%$ \\
\hline MINISTERIO DE DEFENSA & $1.134,73$ & $1.221,47$ & $-86,74$ & $-7,64 \%$ \\
\hline POLICIA NACIONAL & $1.123,44$ & $1.182,71$ & $-59,27$ & $-5,28 \%$ \\
\hline TOTAL & $6.125,22$ & $6.608,42$ & $-483,20$ & $-7,89 \%$ \\
\hline
\end{tabular}

Fuente: Ministerio de Economía y Finanzas 
(USD 1.134,73 millones) y Policía Nacional (USD 1.123,44 millones). Por estas acciones, el nivel de gasto de personal presenta una caída real de USD 601,42 millones, respecto al PGE 2019.

En los gastos corrientes en 2019, el monto más significativo corresponde a los egresos en personal (grupo 51) que suman USD 9.385,38 millones (figura 1), representando $26,41 \%$ del total de egresos del PGE; corresponde a remuneraciones unificadas principalmente de los Ministerios de Educación (USD 2.492,67 millones), Salud Pública (USD 1.605,25 millones), Defensa Nacional (USD $1.221,47$ millones) y Policía Nacional (USD 1.182,71 millones), tal como se puede apreciar en la tabla 4 .

En la figura 2 se muestran los gastos de bienes y servicios de consumo en 2020 alcanzan USD 6.135,53 millones de los cuales USD 3.997,49 millones $(65,15 \%)$ corresponden a la Cuenta de Financiamiento de Derivados Deficitarios (CFDD). La diferencia USD 2.138,04 millones al resto de gastos en bienes y servicios, se registró una disminución de USD 452,46 millones respecto a la Proforma de 2019.

Para 2019, los bienes y servicios de consumo se contempló USD 6.587,99 millones, de los cuales USD 4.228,73 millones $(64,19 \%)$ para la Cuenta de Financiamiento de Derivados Deficitarios - CFDD que financia la importación de derivados deficitarios para garantizar el abastecimiento de combustibles en el país. La diferencia USD 2.359,26 millones al resto de gastos en bienes y servicios.

Para 2020, los egresos financieros (grupo 56) totalizan USD 3.390,00 millones, con una participación de 9,55 \% en los egresos totales, recursos previstos para el pago de intereses de la deuda pública, en mayor parte de los bonos del Estado colocados en el mercado internacional y nacional.

Los egresos financieros (grupo 56) en 2019, totalizan USD 3.365,22 millones, con una participación del 9,47 \% en los egresos totales, recursos previstos para el pago de intereses de la deuda pública, en mayor parte de los bonos del Estado colocados en los mercados internacional y nacional.

Para el 2020, las transferencias o donaciones corrientes (grupo 58) se prevé USD 3.886,33 millones que equivale a $10,95 \%$ de los gastos totales, incluye USD 2.104,76 millones para la seguridad social (IESS, ISSFA, ISSPOL) y USD 1.053,86 millones para el Bono de Desarrollo Humano, Bono Joaquín Gallegos Lara, Pensión de Adultos Mayores y Pensión para Personas con Capacidades Especiales.

En el 2019, para transferencias o donaciones corrientes (grupo 58) se prevé USD 3.433,58 millones, que equivale a 9,66 \% de los gastos totales, incluye USD 1.995,02 millones para la seguridad social (IESS, ISSFA, ISSPOL) y USD 700,45 millones para el Bono de Desarrollo Humano, Bono

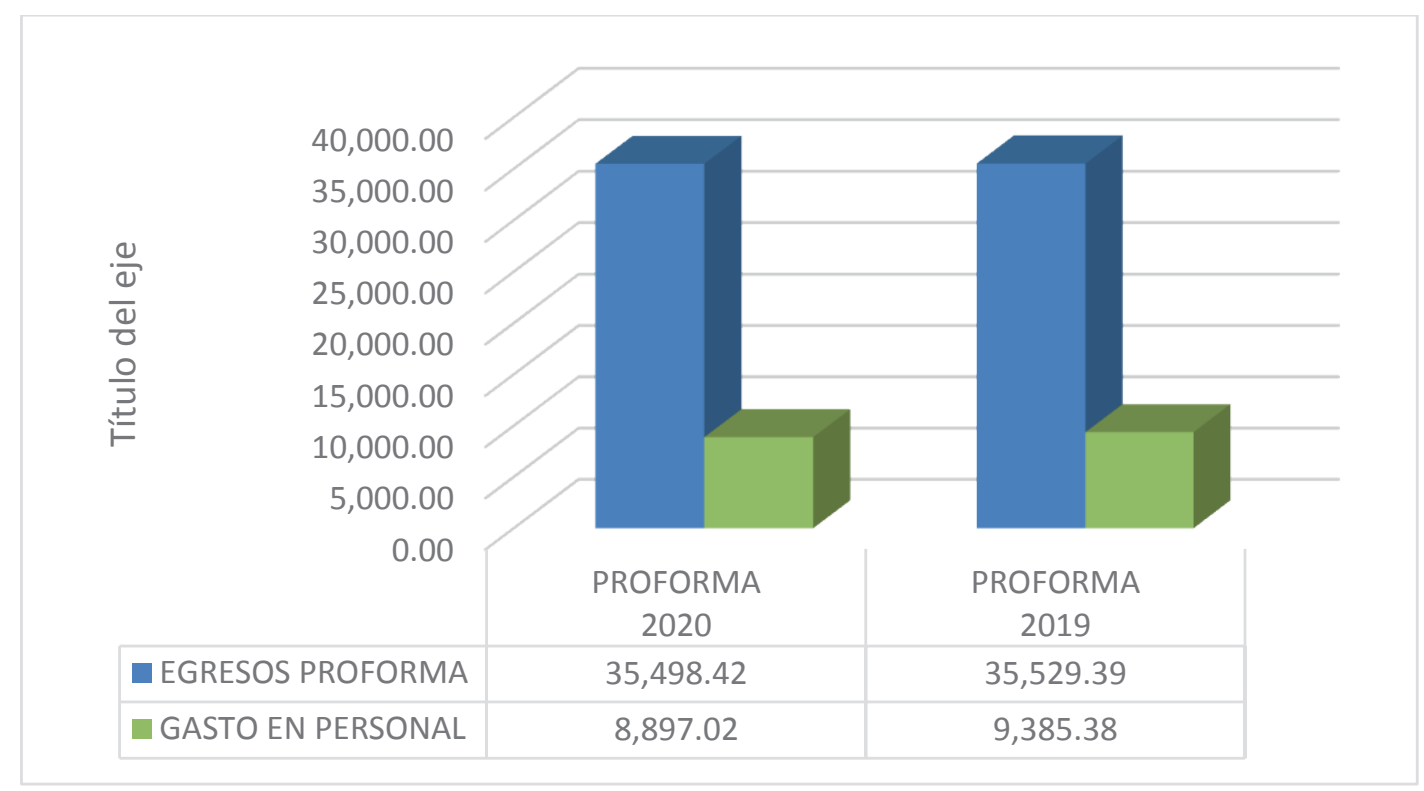

Figura 1. Relación egresos totales vs gastos en personal-Presupuesto 2020 vs. Presupuesto 2019

(en millones de dólares)

Fuente: Ministerio de Economía y Finanzas 


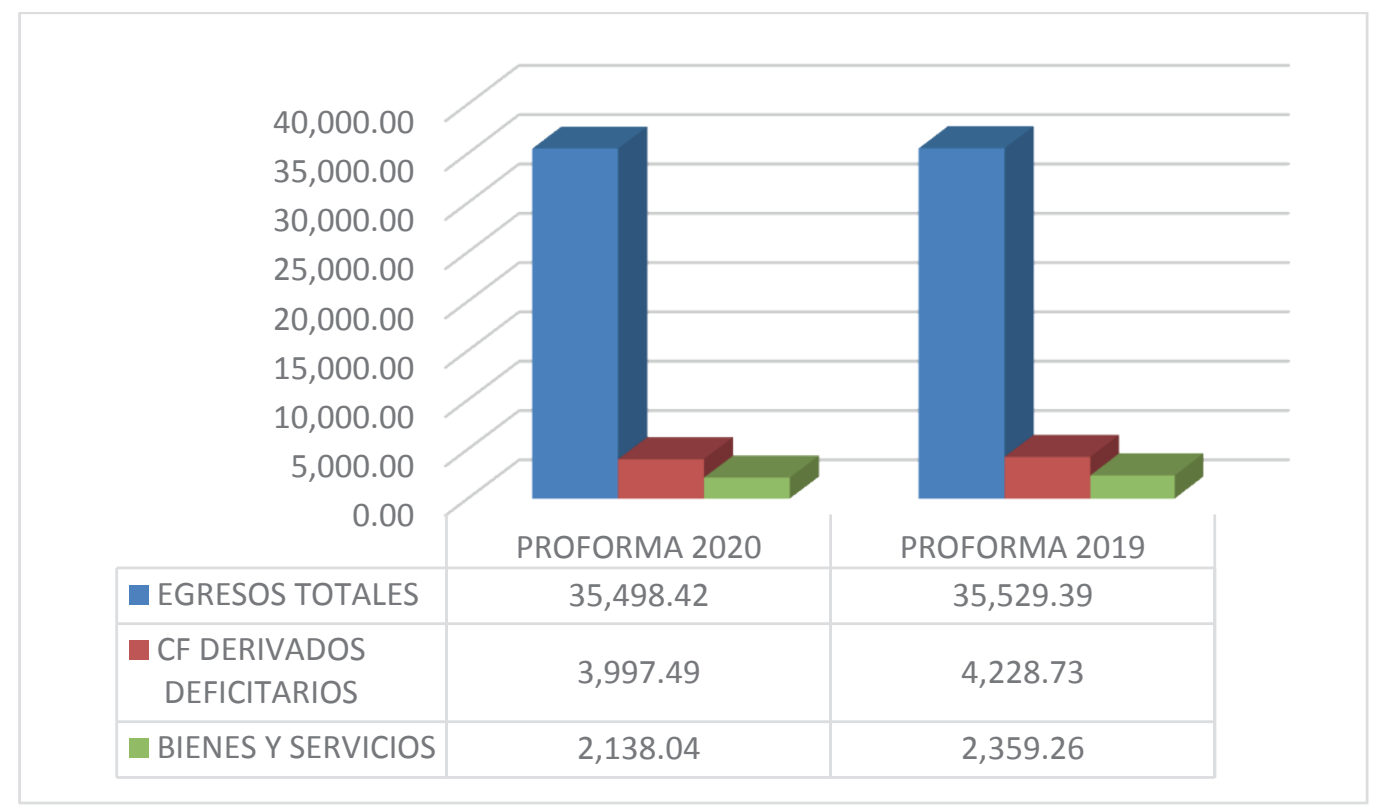

Figura 2. Análisis en gastos de bienes y servicios- Presupuesto 2020 vs. Presupuesto 2019

(en millones de dólares)

Fuente: Ministerio de Economía y Finanzas

Joaquín Gallegos Lara, Pensión de Adultos Mayores y Pensión para Personas con Capacidades Especiales.

En el 2020, respecto a los gastos de inversión y capital, las transferencias o donaciones de capital (grupo 88) son las más significativas con USD 3.715,60 millones y una participación en el total de egresos de 10,47 \% relacionada principalmente con las transferencias hacia los Gobiernos Autónomos Descentralizados que alcanzan USD 3.097,94 millones.

Respecto a los gastos de inversión y capital, las transferencias o donaciones de capital (grupo 88) en el 2019 son las más significativas con USD 3.983,10 millones y una participación en el total de egresos de 11,21 \% relacionada principalmente con las transferencias hacia los Gobiernos Autónomos Descentralizados que alcanzan USD 3.394,49 millones.

Para obras públicas en el 2020 (grupo 75) en la presupuesto se incluyen USD 614,33 millones, con un aporte de 1,73 $\%$ del total de ingresos que corresponde principalmente a programas de infraestructura educativa, equipamiento y mantenimiento en infraestructura de salud, reconstrucción y reactivación productiva de las zonas afectadas por el terremoto de abril de 2016 e incremento de infraestructura del transporte vial, ejecutados por los Ministerio de Educación, Salud y Transporte y Obras Públicas.
En el 2019, para obras públicas (grupo 75) en la proforma se incluyen USD 699,89 millones, con un aporte de 1,97 $\%$ del total que corresponde principalmente a programas Infraestructura Educativa, Reconstrucción y Reactivación Productiva de las Zonas Afectadas por el Terremoto de abril de 2016 e Incremento de Infraestructura del Transporte Vial, ejecutados por los Ministerio de Educación y Transporte y Obras Públicas.

Además, para bienes y servicios para inversión (grupo 73 ) en 2020, se considera USD 1.185,54 millones que equivale a una participación de 3,34 \% del total de egresos, recursos que se destinarán en la adquisición de insumos para el desarrollo de los proyectos del Plan Anual de Inversiones, mientras que en 2019, se considera USD 796,48 millones que equivale a una participación de 2,24 $\%$ del total de egresos

En el 2020, las transferencias o donaciones para inversión (grupo 78) intervienen con 1,64\% al sumar USD 583,30 millones, destacándose el monto previsto para el Bono de la Vivienda con USD 179,70 millones; mientras que en el 2019 las transferencias o donaciones para inversión (grupo 78 ) intervienen con 2,54\% al sumar USD 902,11 millones, destacándose el monto previsto para el Bono de la Vivienda por USD 532,08 millones.

Para amortización de la deuda pública (grupo 96) se estima USD 4.310,73 millones, lo que representa el 12,14\% 
del total de egresos de la Proforma, recursos contemplados principalmente para el pago de bonos colocados en el mercado nacional y de créditos generados con gobiernos, organismos gubernamentales y multilaterales, entre otros; mientras que para el 2019 para amortización de la deuda pública (grupo 96) se estima USD 3.851,67 millones, lo que representa el 10,84\% del total de egresos de la Proforma, recursos contemplados principalmente para el pago de bonos colocados en el mercado nacional y de créditos generados con gobiernos, organismos gubernamentales y multilaterales, entre otros.

\section{DISCUSIÓN}

Si hacemos un análisis del Presupuesto General del Estado 2020 tenemos que asciende al valor de USD 35.498,42 millones, de los cuales: USD 23.853,05 millones corresponden a ingresos corrientes que representan el 67,19\% de la estructura total; mientras que los ingresos de capital estimados en USD 2.712,76 millones, aportan con el 7,64\%; en tanto que el restante $25,16 \%$ constituye los ingresos de financiamiento con un valor de USD 8.932,61 millones. Estos recursos de financiamiento suman USD 8.932,61 millones, de los cuales USD 4.709,82 millones corresponden a deuda externa que representan el 13,27\% del total del Presupuesto General del Estado y el 4,26 \% del PIB; dentro de la estructura de la deuda externa, las fuentes de financiamiento se encuentran distribuidas entre préstamos con Organismos Multilaterales por USD 2.687,97 millones; operaciones con otras entidades internacionales por USD 1.819,28 millones; Gobiernos por USD 202,57 millones. La deuda interna es de USD 1.955,11 millones y proviene del financiamiento interno, de la negociación y entrega directa de papeles fiduciarios colocados en el mercado financiero nacional; el resto de ítems de esta categoría, corresponden a saldos disponibles, principalmente de préstamos que ascienden a USD 2.267,68 millones. $\mathrm{Al}$ revisar estas cifras del Presupuesto General del Estado vemos que la deuda pública y su costo ejercen una presión fiscal que con el tiempo se puede volver insostenible, así el gasto público no es eficiente porque no sirve para su fin inicial que es brindar servicios públicos de calidad, ya que un gran porcentaje se destina para servicios del pago de la deuda, y más aún, la solución no está en buscar más endeudamiento sino en generar políticas de comercio exterior que permitan mejorar la balanza de pagos y que esta sea favorable. Recordemos que la dolarización se sostendrá mientras exista liquidez en el mercado local, no podemos buscar fuentes de financiamiento que incluyan sacrificios a la sociedad. Se debe mirar desde una óptica donde el ser humano esté por encima del capital. El Fondo Monetario Internacional (FMI) ha solicitado varias medidas de ajuste fiscal, tales como una reforma tributaria, reducción del tamaño del Estado y reformas al manejo de la política fiscal, laboral y monetaria que todavía se encuentran postergadas, al igual que la eliminación de los subsidios a los combustibles, que generó el caos en el país en octubre de 2019, en el que la presión ciudadana hizo que el gobierno derogue el Decreto Ejecutivo que eliminaba este subsidio; sin embargo, se debe hacer un reajuste al acuerdo si el Ecuador quiere mantener una línea de crédito fresca que ayude a superar la crisis que actualmente se ve agravada por la pandemia del coronavirus y la baja del precio del petróleo a menos de 30 dólares, cuando el Estado lo presupuestó a 53 dólares por barril. Así, hemos pasado de una política fiscal expansiva a una restrictiva, con una consecuente recesión y reducción del empleo, tanto público como privado; lo paradójico de este escenario es que el sector bancario logró utilidades netas, descontando impuestos y beneficios de ley, que sumaron USD 616 millones, frente a USD 554 millones de 2018, según la Asociación de Bancos Privados del Ecuador (Asobanca). Fortalecer los acuerdos comerciales en condiciones favorables para el país, potenciar el turismo y generar un marco jurídico atractivo para la inversión extranjera directa, así como la diversificación de la producción interna que permita lograr productos de calidad que generen divisas para el país y mejoren las condiciones de la clase laboral del país, son sin duda medidas lógicas pero difíciles de implementar en un país donde se genera ambientes adversos por escenarios políticos y económicos que nos son favorables. Optimizar el gasto público es posible, pero el camino de la austeridad no puede tener una sola vía: la reducción de la masa salarial, los servicios públicos deben ser eficientes y eso responde en gran medida a la calidad de servicios que se otorga al ciudadano.

\section{REFERENCIAS}

Amighini, A., Brancaccio, E., Giavazzi, F. y Messori, M. (2012). A new textbook approach to macroeconomics: A debate. Rivista di Politica Economica, 3(7-9), 101-129.

Armijo, M., y Espada, M. (2014). Calidad del gasto público y reformas institucionales en América Latina. Santiago de Chile: Naciones Unidas.

CEPAL (Comisión Económica para América Latina y el Caribe). (2006). La protección social de cara al futuro: acceso, financiamiento y equidad (LC/G.2294 (SES$.31 / 3) / E$ ), Santiago de Chile.

Dornbusch, R. y Fischer, S. (1995). Curso breve de macroeconomía. Madrid: McGraw-Hill.

Ecuador, Constitución de la República del Ecuador (2008). Asamblea Nacional del Ecuador. Quito. Recuperado de: https://www.oas.org/juridico/pdfs/mesicic4_ecu_ const.pdf 
Ecuador, Ministerio de Economía y Finanzas. (2019). Proforma Presupuestaria 2019. Recuperado de: https:// www.finanzas.gob.ec/proforma-enviada-a-la-asamblea-nacional-2019/

Ecuador, Ministerio de Economía y Finanzas. (2020). Proforma Presupuestaria 2020. Recuperado de: https:// www.finanzas.gob.ec/pro-forma-presupuestaria-2020/

Registro Oficial de la República del Ecuador. (2019). Edición especial No. 187, diciembre 2019. Recuperado de: https://www.registroficial.gob.ec/index.php/registro-oficial-web/publicaciones/ediciones-especiales/ item/12357-edicion-especial-no-187
Romero, E. (2012). Planeación y Presupuesto Público. Recuperado de: https://app.vlex.com/\#WW/vid/58115128

Ruiz, R. (2010). Sobre la evolución del Gasto Público social en América Latina y sus papel para la estabilización económica. Serie Macroeconomía del Desarrollo 102, CEPAL, Abril de 2010, Santiago de Chile. 
